Petrillo, Pecchia, De Felice/A Decision Support Tool to Support Innovative and Strategic Process To Be Submitted to the International Symposium of the Analytic Hierarchy Process 2014,

Washington D.C., U.S.A.

\title{
A DECISION SUPPORT TOOL TO SUPPORT INNOVATIVE AND STRATEGIC PROCESSES
}

\author{
Antonella Petrillo \\ University of Naples "Parthenope" \\ Naples, NA, ITALY \\ E-mail: antonella.petrillo@uniparthenope.it \\ Leandro Pecchia \\ School of Engineering, University of Warwick \\ Coventry CV4 7AL, UK \\ E-mail: L.Pecchia@warwick.ac.uk \\ Fabio De Felice \\ University of Cassino and Southern Lazio \\ Cassino, FR, ITALY \\ E-mail: defelice@unicas.it
}

\begin{abstract}
In recent years a growing number of companies modified their innovation process. Especially after the recent financial downturn, companies are looking for much more efficient and creative business processes.

The aim of the presented paper is to present a decision support tool or in other words a software system for the application of the AHP method to support innovative and strategic process. Few studies propose analytic quantitative methods to elicit user/stakeholders needs, and among those a method that seems to be particularly effective to elicit user need was the Analytic Hierarchy Process (AHP).
\end{abstract}

Keywords: innovation, strategic decisions, DSS, AHP. 
Petrillo, Pecchia, De Felice/A Decision Support Tool to Support Innovative and Strategic Process To Be Submitted to the International Symposium of the Analytic Hierarchy Process 2014, Washington D.C., U.S.A.

\section{Introduction}

In the last century innovation has been identified as a critical business process. Recently, research works and practical needs of many companies have converged in a common purpose: to find out those proper elements capable of acting as key drivers of innovative processes.

Firms' dynamical perspective requires dynamical capabilities of managers, critical to successfully manage firm over time. Thus it is need to provide businesses with useful decision tools (Rogo et al., 2014).

The AHP method can be very useful to reach this aim (Saaty, 1977). Its hierarchical approach allows the construction of a consistent framework for step-by-step decisionmaking, breaking a complex problem into many small less-complex ones that decisionmakers can more easily deal with.

This paper presented a software tool based on AHP method for develop and assess the strategic performance within a firm.

\section{Literature Review}

As far as author knowledge, this is the first tool specifically designed to apply the AHP to support strategic process and to the user need elicitation. This allows its use to users that are not expert of the AHP. Moreover, the web platform is designed to facilitate the aggregation users of AHP (Pecchia et al., 2013).

In literature there is no evidence of other applications based in the above approach.

\section{Hypotheses/Objectives}

We consider the innovation process as divided in six stages: creation, filtering, decision making, acknowledgment, implementation and exploitation. During the creation phase a member of the community creates a new idea. A complex idea often involves several aspects and the knowledge about them is distributed among several people. For this reason we developed a web application designed following AHP principles.

\section{Research Design/Methodology}

The development of an efficient and creative business processes requires decision makers to follow a structured multidimensional and multi-factorial process (Figure 1), consisting in the following steps:

1. Need analysis: definition of the problem to be solved via: (a) identification of the needs that have to be satisfied; (b) classification of these needs into meaningful categories and sub-categories; (c) prioritizing them according to their relative importance (scoring);

2. Strategy identification: to individuate all the healthcare technologies which can satisfy these needs;

3. Multidimensional evaluation: to assess which technology satisfies the identified needs better in each dimension;

4. Data analysis: Multi-Criteria Decision Making (MCDC);

5. Relative assessment: compare all the technologies;

6. Dissemination: inform the scientific community; 
Petrillo, Pecchia, De Felice/A Decision Support Tool to Support Innovative and Strategic Process To Be Submitted to the International Symposium of the Analytic Hierarchy Process 2014, Washington D.C., U.S.A.

7. Audit: will the result change over the time?

8. Results: implementation.

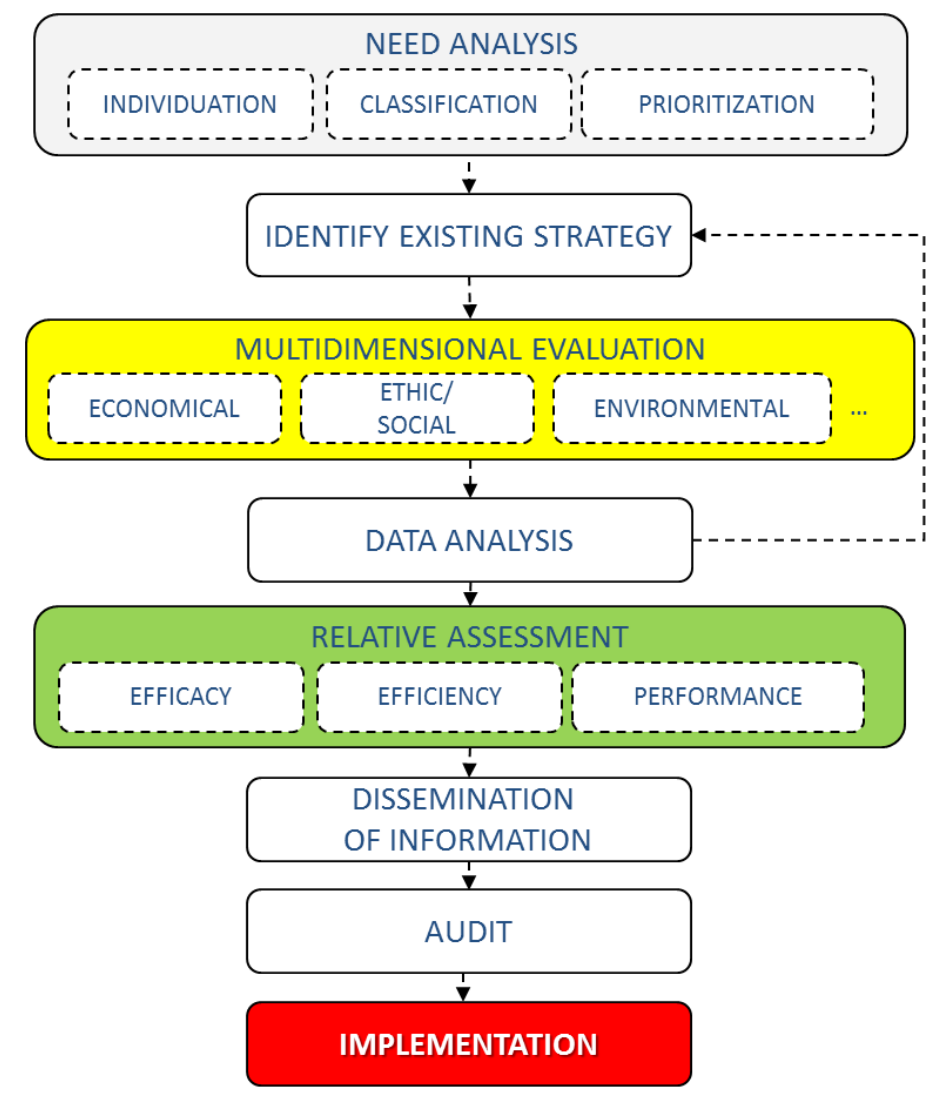

Figure 1: Methodological approach

The system developed consist of an App for iPad, a web portal, two databases and several web services. The architecture is described in Figure 2.

This App can be used alone, to support an AHP application, or in strong relation with the web portal, which is mainly meant to facilitate AHP applications.

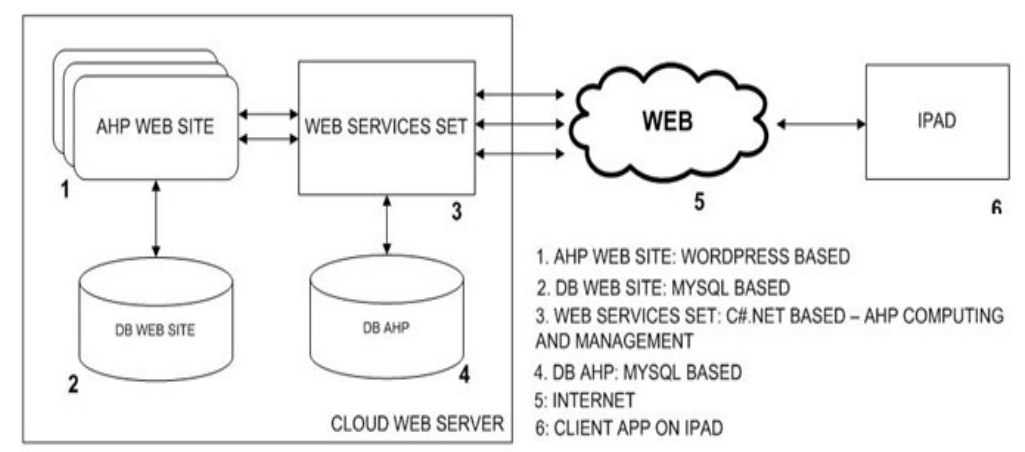

Figure 2: Architecture

International Symposium of 
Petrillo, Pecchia, De Felice/A Decision Support Tool to Support Innovative and Strategic Process To Be Submitted to the International Symposium of the Analytic Hierarchy Process 2014, Washington D.C., U.S.A.

In Figure 3 is shown an example of web portal screenshot.

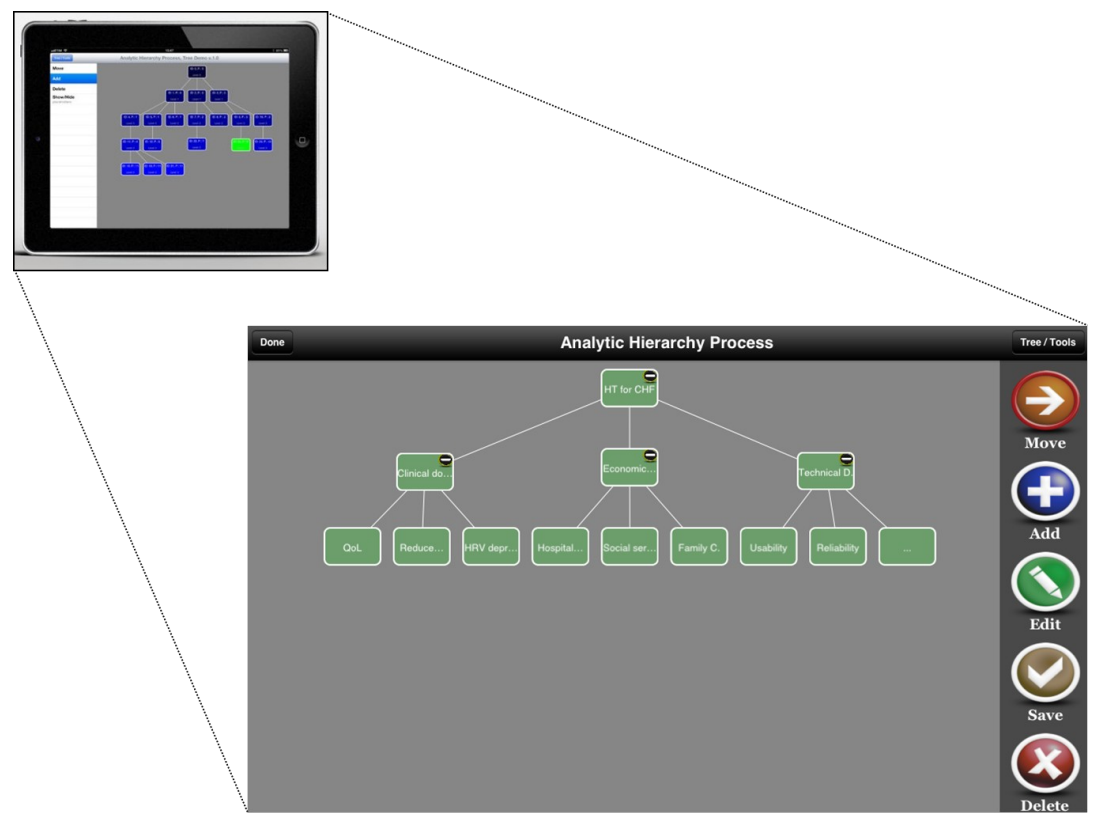

Figure 3: Example of screenshot

Main functionalities are:

- Create the Hierarchy: problem definition/hierarchy draft.

- Download an existing hierarchy: to be used as starting model.

- Invite domain experts: study piloting.

- Amend the hierarchy.

- Invite responders.

- Participate to the study.

- Analyse and Pool results.

- Generate a report.

- Publish: upload on the portal hierarchy, results, reports, etc.

\section{Data/Model Analysis}

This paper will present the results of an ongoing research that is not yet complete.

\section{Limitations}

The proposed method has been verified for a limited number of case study. Further research will fill up the gap.

\section{Conclusions}

This paper offers a practical and replicable managerial tool to support manager and practitioners in sustaining the value creation through innovation practices. 
Petrillo, Pecchia, De Felice/A Decision Support Tool to Support Innovative and Strategic Process To Be Submitted to the International Symposium of the Analytic Hierarchy Process 2014, Washington D.C., U.S.A.

From this point of view AHP is particularly effective. Thus, this paper presented a software tool based on AHP useful to manage complex decision in complex environmental. The web platform is designed to facilitate the aggregation users of AHP for innovative process. It can be used by users that are not expert of the AHP.

\section{Key References}

Pecchia L, Martin J.L., Money A.G., Barnet J. (2013). Application of analytic hierarchy process for user needs elicitation: a preliminary study on a device for auto-injection of epinephrine. In: Health Information Science. Springer, pp 258-264

Rogo R., Cricelli, L., Grimaldi G. (2014). Assessing the performance of open innovation practices: A case study of a community of innovation. Technology in Society 38 (2014) 60-80.

Saaty T.L. (1977) A scaling method for priorities in hierarchical structures. Journal of Mathematical Psychology 15:8 